\title{
Investigating the Contribution of Atmospheric Sources to the Mo Surface Cycle
}

\author{
EDEL O'SULLIVAN ${ }^{1}$, THOMAS F. NÄGLER ${ }^{1}$, NIKLAUS \\ WABER $^{1}$, MARIE-CLAIRE PIERRET ${ }^{2}$ AND ANNE K.C. \\ KAUFMANN, PHD ${ }^{1}$ \\ ${ }^{1}$ University of Bern \\ ${ }^{2}$ LHyGeS CNRS Université de Strasbourg \\ Presenting Author: edel.osullivan@geo.unibe.ch
}

Accurate mass balance modelling of the ancient Mo cycle relies on key input parameters derived from that of the modern day. The Mo isotope budget of the surface environment has been increasingly well-characterised in recent decades. An ongoing debate is the origin of isotopically heavy river waters relative to continental sources, thus far explained mainly as either a reflection of specific bedrock sources, or the retention of light isotopes within the weathering profile.

Here we present [Mo], Mo-, Sr- and O isotope, and major cation data of precipitation in central Europe to evaluate atmospheric input of Mo as a hitherto unconstrained component of the Mo mass balance. So far, two studies have reported heavy $\delta^{98} \mathrm{Mo}$ compositions of precipitation in close proximity to the Pacific Ocean (Oregon Coast; Hawai'i), relative to continental sources. Nägler et al. (2020) identified a marine influence on stream waters in France based on coupled Mo- and Sr- isotope signatures, suggesting an input of isotopically distinct marine aerosols to the Mo surface cycle giving rise to heavy stream water signatures.

To test this hypothesis, we evaluate the distal effect of marine aerosols in the inner-continental environment. We collected 11 samples of snow from the High Alpine Research Station (HFSJG) and the Jura Mountains in Switzerland, as well as a sample from the Environmental Hydro-Geochemical Observatory (OHGE) in France (location of sample site of Nägler et al., (2020)). Filtered samples are evaporated in a Savillex distillation unit. Additionally, filtered dust particles are leached and analysed in parallel, as well as stream waters directly draining the snow cap at the HFSJG.

As expected, initial results from the HFSJG show narrow variation of $\delta^{98}$ Mo within the range of continental crustal values (ca. 0.0-0.8\%o), indicating that an influence from marine aerosols is not discernible far from ocean water bodies, and/or at high altitudes. The results of snow and river water samples from all locations are discussed in comparison to previous work and have implications for the Mo surface cycle in terms of proximity to marine sources.

Nägler, T., et al. (2020), Biogeochemical Cycles: Ecological Drivers and Environmental Impact, 163-189. 